\title{
Transforming Sovereign Debts into Perpetuities through a European Debt Agency
}

\author{
Massimo Amato (Bocconi University) \\ Everardo Belloni (Polytechnic University of Milan) \\ Paolo Falbo (University of Brescia) \\ Lucio Gobbi (University of Trento)
}

April 18, 2020

\begin{abstract}
This paper outlines the main operating framework of a Debt Agency (DA) for the management of the Eurozone sovereign debts. The framework leverages on the potential irredeemable nature of sovereign debts in order to build a common bond. Structurally filtering liquidity risk, the DA can price the Member States' installments by referring only to their fundamental risk. The common bond issued by the DA then avoids mutualisation by design, hence it can be directly bought by the ECB. Thanks to its structural intertemporal sustainability, the DA's framework sketched here can serve as a benchmark for institutional and political decisions.
\end{abstract}

\section{Introduction}

In a moment of potential global turmoil, the shortage of safe assets is one of the major problems facing the global economy and attempting the stability of the financial markets (Carney 2019).

In addition to that empirical problem, there is the theoretical one, which is reflected in the lack of a widely agreed definition for safe asset.

This is why in this contribution we adopt the larger and more formal definition proposed by Caballero et al. (2017), with the aim of further refining it: "a safe asset is a simple debt instrument that is expected to preserve its value during adverse systemic events".

Three elements are relevant in this definition: 1) the relative simplicity of the instrument (better plain vanilla than structured); 2) the expected stability of its long-term value; 3 ) its resilience to all sorts of events, also and especially to systemic ones. We are stressing this point because, as we shall see, all the three elements need to be present for an asset in order to be safe. Inversely, the lack of only one of them jeopardizes the safety of the asset.

Before the Great Financial Crisis (GFC) of 2007, the issue of the safe assets shortage had been investigated mainly in relation to global imbalances. In 
particular, several contributions showed the strong demand for safe and foreign assets by emerging countries given their inability to produce them in the amounts necessary for the growth of their economies and the stability of their currencies (Bernanke, 2005; Caballero et al., 2008; Gourinchas and Rey, 2007) . After the Great Financial Crisis, the shortage of safe assets has become structural even in advanced economies, due to a joint increase in their demand and a reduction in their supply (IMF 2012).

The demand of safe assets depends on the prominent role that this asset class plays in international financial markets daily operations (Golec and Perotti 2017 for a review). Among the most important, safe assets are used by banks and various financial institutions as high-quality (high-liquidity) collaterals in transactions. Recently, new banking regulation boosts safe assets demand for prudential purposes (for example, Basel III introduces the "liquidity ratio" and increases weights of the "non safe" sovereign debts for capital requirements). Moreover, the core business of pension funds and insurance companies is characterized by a regular outflow of financial resources which justifies a structural allocation of safe assets in their portfolios (due to the expected stability of their long term positive yield). Furthermore, safe assets are widely used by central banks for both conventional and unconventional monetary policies and by investment funds as a benchmark to price riskier assets as well as a store of value.

For what concerns the supply side, safe assets can in principle be issued by both public and private financial institutions. The high-ranking sovereign debts are nevertheless the safest asset par excellence, given the ability of these governments to collect income and property taxes. Yet, the supply of public safe assets is constrained by country's fiscal capacity and creditworthiness. Reinhart and Rogoff (2009) argue that in times of crisis sovereign debts tend to increase while their credit standing tend to lower. This dynamic can lead to a shortage of safe assets. Gorton et al. (2012) show that the demand for safe assets for the American economy since 1952 has remained constant. This implies that if the availability of public safe assets varies according to the conditions of the economic cycle, the gap between supply and demand has to be filled by private safe assets (Krishnamurthy and Vissing-Jorgensen 2015). The latter can be however considered only as "quasi safe", given their greater vulnerability respect to public guaranteed assets in times of crisis. Although all high rating assets incorporate a liquidity premium over other classes of securities, high rating public assets also exhibit a safety premium that incorporates the certainty that all the financial obligations will be met. Krishnamurthy and Vissing-Jorgensen (2012) find a strong evidence that Treasury debts incorporate a safety premium which displays an inverse relationship with the amount of the outstanding debt of the issuing country.

As many recognize, a safe asset shortage (due to the lack of one of the above mentioned three necessary elements) has significant macroeconomic implications. Caballero and Fahri's safe asset mechanism (SAM) (Caballero and Fahri, 2015) highlights the fact that at the zero lower bound the safe assets market does not clear. Whenever the demand of safe assets increases and the equilibrium safe interest rate is negative, a safety-trap appears. To some extent, 
SAM model is comparable to the modern version of Keynesian liquidity trap (Krugman 1998). However, despite the similarities between the two models, quantitative easing policies are more effective in SAM than in liquidity trap environments. The opposite occurs when considering the use of the fiscal policy and forward guidance. Gorton and Ordonez (2014) show that a shortage of safe assets as collateral constrains firms' borrowing capacity. This can trigger a recession phase or act as a financial accelerator that amplifies a shock that hit an economy (Panetta et al. 2009). Moreover, a shortage of safe assets encourages governments issuing safe assets to increase their public debts. This is true as long as the cost of public debt is lower than the rate of growth of the issuer's country (Blanchard and Summers 2019). In this way, the issuer's country becomes exposed to the risk of a coordination-failure run on public debt (Farhi and Maggiori 2016).

Among the most advanced economic areas, the problem of the shortage of safe assets is particularly accentuated in Europe. The objective of this contribution is then to present a general framework for the implementation of a European safe common asset, issued by a European Debt Agency, which could be able to fix most of the critical issues that prevented the implementation of the proposals emerged so far. Since the beginning of the European financial and economic crisis, many proposals of creating a public safe asset by pooling euro area debts into a bond backed by member countries were at core of European agenda (see De Grauwe and Moesen 2009 ; Gros and Micossi 2009; Bonnevay 2010; Monti 2010; Juncker and Tremonti 2010; Delpla and Weizsäcker 2010, 2011; Beck et 2011; Brunnermeier et al. 2011, 2017; Hellwig and Philippon 2011; Ubide 2015).

Indeed, since the establishment of the monetary union until the European debt sovereign crisis, most of the bonds from euro-area countries enjoyed a safe asset status that many of them lost during 2010 financial turmoil. These events show that the resilience of an asset, hence its safety, can be affected by events. If the GFC has led many Member States' (MS) debts of the Eurozone to loose their status of SA, and strengthened the SA status of others through a flight to quality, it is questionable that the systemic adverse event of a shutdown of the euro could preserve the SA asset status even for the strongest MSs.

Figure 1 below shows that at present the level of Eurozone safe assets does not account for more than $60 \%$ of its total outstanding debt, corresponding to less than $50 \%$ of Eurozone GDP (the ratio of safe assets on GDP for the euro area is $46 \%$, whereas the same ratio is $80 \%$ in the UK and $106 \%$ in the US). Too little of a level to make the economy working properly, especially if we consider that the requirement by the financial sector alone should account for almost $30 \%$ of GDP in safe assets (an estimated of $20 \%$ of overall banks deposits).

Currently the European Union needs a safe asset for different reasons (for an overview see Constâncio 2019). Without a European public and common safe asset, it will be very difficult to break the perverse link between the national banking systems and their public debt. Indeed, the trend towards home bias cannot be resolved simply by diversifying bank portfolios. 


\begin{tabular}{|c|c|c|c|c|}
\hline Years & 2017 & & Increase & S\&P \\
\hline Austria & 289843.10 & 285287.30 & $-1.57 \%$ & AAt \\
\hline Belgium & 454293.30 & 460038.70 & $1.26 \%$ & AA \\
\hline Cyprus & 18814.10 & 21256.30 & $12.98 \%$ & BBB- \\
\hline Estonia & 2219.20 & 2174.20 & $-2.03 \%$ & AA- \\
\hline Finland & 137391.00 & 138412.00 & $0.74 \%$ & AAt \\
\hline France & 2258656.00 & 2315266.00 & $2.51 \%$ & AA \\
\hline Germany & 2118963.40 & 2069007.10 & $-2.36 \%$ & AAA \\
\hline Greece & 317484.00 & 334721.00 & $5.43 \%$ & BB- \\
\hline Ireland & 201363.00 & 205977.60 & $2.29 \%$ & AA- \\
\hline Italy & 2328697.20 & 2380305.70 & $2.22 \%$ & BBB \\
\hline Latvia & 10352.40 & 10600.60 & $2.40 \%$ & A- \\
\hline Lithuania & 16630.40 & 15425.10 & $-7.25 \%$ & A \\
\hline Luxembourg & 12696.60 & 12609.70 & $-0.68 \%$ & AAA \\
\hline Malta & 5682.10 & 5641.10 & $-0.72 \%$ & A- \\
\hline Netherlands & 420056.00 & 405504.00 & $-3.46 \%$ & AAA \\
\hline Portugal & 246966.50 & 249143.10 & $0.88 \%$ & BBB \\
\hline Slovakia & 43369.50 & 44321.90 & $2.20 \%$ & At \\
\hline Slovenia & 31862.70 & 32222.90 & $1.13 \%$ & AA- \\
\hline \multirow[t]{2}{*}{ Spain } & 1145098.00 & 1173303.00 & $2.46 \%$ & A- \\
\hline & 10060438.50 & 10161217.30 & $1.00 \%$ & \\
\hline Stocks & Cost PC & Rating & utstanding 2018 & $\mathrm{PC}$ \\
\hline GDP Eurozona & 11954373.29 & AAA & 2551.72 & $25 \%$ \\
\hline Eurozone Safe Asset & 5520995.50 & AA & 3375.63 & $34 \%$ \\
\hline Proportion & $46.18 \%$ & A & 1221.13 & $12 \%$ \\
\hline Deposits & 17000000.00 & BBB & 2594.48 & $26 \%$ \\
\hline Banks Needed & 3400000.00 & BB & 317.48 & $3 \%$ \\
\hline Banks Proportion on & $28.44 \%$ & Total & 10060.44 & $100 \%$ \\
\hline
\end{tabular}

Figure 1: Outstanding debts Eurozone, source Eurostat (2019)

Enforcing debt diversification to European banks could spread the risk across European financial system and furthermore it does not take into account the fact that given the rollover costs it could be very difficult to change the composition of their investors (Constâncio 2018; Giuzio et al. 2016). What Eurozone needs, since its very inception, but even more after the 2010 turmoil, is a common safe asset capable of structurally reabsorbing the current divergence in yields among Eurozone MSs' sovereign bonds, which is far wider than their rating would justify. In the absence of a common public safe asset, financial operators could be forced to rely on "quasi safe private portfolios" of not-so-safe public assets, or on private "quasi safe assets" that could possibly feed bubbles and/or quickly lose their credit standing in turmoil (Gorton and He 2016; Greenwood et al. 2015). In a word, one cannot rely on agents in the system to prevent the risk of the system, simply because, in order to make their optimization allocation choices, they need an external benchmark. One of the objectives declared by European legislators is to move to a complete Capital Market Union. But, without a liquid and deep public bond market it is very difficult to hypothesize that the goal can be achieved. Furthermore, the heterogeneity between national public debt yields makes it difficult for financial operators to extract information from the term structure of interest rates of the ECB. Finally, the clear need of an expansion of public deficits due to the common economic crisis triggered by 
the Covid pandemic will put an asymmetric pressure on the financing of each MS, thus posing the problem of a common solution capable of avoiding any sort of undesired and politically unviable debt mutualization.

Our proposed framework is based on the following core elements.

1. A Debt Agency (DA) at Eurozone level, owned by Eurozone MSs (see section 3), issuing debt securities characterized by high creditworthiness with funding to be carried out on the primary market.

2. A mechanism of replacement of expiring government bonds with new Agency bonds, capable of transforming MS's debts into perpetuities whilst continuing to offer to the markets bonds characterized by finite maturities.

3. A procedure to determine the "cost of funding" for each MS according to a country's "Own Fundamental Risk Based Mechanism", financially fair, retrieved from "Through the Cycle" (TTC) transition matrices.

4. An insurance-based architecture to address the DA's solvency requirements.

Starting from the assumption that, if endowed with a common bond, the Eurozone as such entails lower probabilities to fail, the DA is based on flow regulation mechanisms that cover the expected losses of the weaker countries, including the probabilities of systemic crisis. Therefore, the DA is preventively protected from the risk of insolvency both in the ordinary economic regime and during systemic stress. As a consequence, DA bonds will be correctly perceived by the market as a safe asset, since it is possible to demonstrate that the DA would be also able to "withstand" even the extreme hypothesis of a temporary suspension of payments from all the MSs.

The DA framework is perfectly capable of adapting to the policy configurations that could be adopted by European legislators. Here we describe the fundamental option in which every country contributes proportionally to its fundamental risk.

The paper is divided into five sections. First section introduces. Second section presents a review of the literature. The third describes our proposal and technical details. The fourth section deals with simulations, while the fifth is devoted to conclusions.

\section{Literature review}

The shortage of safe assets in the Eurozone and the lack of a true European bond are the two facets of the same problem. Mostly in case of extreme systemic events the resilience of a common bond is greater than the sum of the single MSs' sovereign debts (see also section 3, remark 6, with regard to the "pooling effect" of the DA's portfolio). The problem has emerged in all its clarity since the early stages of the European sovereign crisis, when the spreads between the yields of public debts begun to widen due to sudden stop in capital inflows that 
caused a "flight to quality" to Northern countries sovereign debts, and a "flight from liquidity risk", which triggered a doom loop of self-fulfilling expectations, that eventually led to an overshooting to market yields on public debts of the downgraded MSs .

The emergence of spreads can not be solved in the current frame of the Eurozone by a proactive action of the ECB, which cannot act on the markets outside the capital key clause, unless for short periods of derogation. So, the ECB has been effective in stopping the absolute growth of certain spreads, but ineffective in reabsorbing the divergence between MSs' bonds yields, precisely because of the capital key. In the absence of a Eurozone Treasury, issuing fully mutualized bonds analogous to US T-bills, the ECB cannot but follow the capital key rule.

From that time on, several proposals have been put forward, by both economists and politicians. Initially, these proposals mainly focused on the creation of "Eurobonds" collectively guaranteed by member countries, thus involving a commitment to mutualisation. Later, given the lack of a political consensus on mutualisation among Eurozone countries, the focus shifted to reform projects entailing the least amount of public guarantees possible. For an accurate overview of the main single proposals we suggest Claessens et al. (2012) and Leandro and Zettelmeyer (2018a).

In this section, we are reasoning in terms of four "ideal types". Each of them can be seen as particular combination of pooling, tranching and public guarantees, with the common aim to achieve risk filtering. In the following, we will present the layout of the ideal types, with a view to the way in which the three aforementioned dimensions are balanced in each one.

The first type entails a mix of pooling and tranching without any form of public guarantees (Brunnemeier et al. 2011, 2017; ERSB 2018). In this case pooling precedes tranching. In this kind of proposal, the safe asset is issued by a public financial intermediary or, indifferently, by several private intermediaries. Each intermediary would issue securities into different tranches. These bonds would be backed by a portfolio of diversified sovereign securities. The installments that intermediaries would pay on the securities issued would be covered by the flow of interests generated by the underlying portfolio. Bonds are divided into two tranches: a senior one (European Senior Bonds, ESB) and another tranche, subordinate to it (European Junior Bonds, EJB). It is clear that the proportion between ESB and EJB tranches determines the degree of safety of the ESB. However, on the other side it determines also the potential insecurity of the EJB. Indeed, a system of this kind has certainly the advantage of creating a safe asset without the need for public guarantees, since risk filtering is obtained by diversifying the underlying assets portfolio and through tranching. Nevertheless, three main problems could arise in this context (De Grauwe and Ji 2018; Gabor and Vestergaard 2018):

1. in the event of a systemic crisis, with bankruptcies from different countries, it is not so sure that ESB would remain safe assets;

2. the EJB market could easily become illiquid during turmoil, thus creating 
many problems for the refinancing of the outstanding public debt;

3. the creation of a safe asset market is complementary to public debt securities markets.

The evaluation of the senior tranche as equally safe as the highly rated sovereign bonds is very unlikely and cannot prevent flight to quality dynamic during turmoils.

The second type of proposal reverses the temporal order between tranching and pooling. Wendorff and Mahle (2015) as well as Leandro and Zettelmeyer (2018a) propose to carry out a national tranching, thus creating a senior debt segment and then another subordinated to it. Later, a financial intermediary could issue a safe asset backed by a diversified portfolio of senior sovereign bonds. The strengths of this proposal are essentially three:

1. it creates a European safe asset without the need for public guarantees, as the first type does

2. a diversified portfolio of senior sovereign bonds would have the advantage of being very stable

3. tranching would induce national states to implement virtuous fiscal policies in order to prevent junior bonds from becoming illiquid or too expensive.

In return, the main weakness of this type of proposal is due to the possibility that, in case of systemic or idiosyncratic shocks, even a well-disciplined country could be unable to finance the rollover of junior bonds. Moreover, self-fulfilling expectations of default could arise due to the way in which public debt would be issued. In fact, the market sentiment towards junior public bond could be very week and subject to sudden changes. On the other side, for countries such as Greece, Italy and Portugal, in order to ensure that their senior tranche would be truly safe, the proportion of outstanding junior debt would be very high. Furthermore, in the case for instance of huge external supply shocks, this very uncomfortable situation could also become common to other countries. In summary, this proposal may be able to create safe assets (strengthening the senior tranche of each participating country more efficiently than in the previous case), but for the same reason it could weaken the solvency and liquidity of junior public debts.

The third type goes a very different way, since it eliminates tranching and brings into play a Debt Agency (Junker and Tremonti 2010; Monti 2010; Leandro and Zettelmeyer 2018b). In this case, the safe asset would be issued by a public or semi-public Debt Agency with adequate capital endowment or a preferred credit status. Leandro and Zettelmeyer (2018b) analyze three variants of this proposal.

1. In the first variant, the Debt Agency would purchase outstanding sovereign debt on secondary markets. This "sovereign portfolio" should guarantee 
the returns to finance the installments of the safe asset. Moreover, the Debt Agency should be adequately capitalized in order to guarantee the asset safety. The strong point of this variant is to issue a safe asset without any need for tranching. This occurs admittedly at the cost of adequate capitalization.

2. In the second variant, the Debt Agency would issue a safe asset backed by a diversified portfolio of European public debts bought at their face value. The installments of the safe asset would be than charged on to the sovereigns in proportion of the amount of each national debt purchased by the Debt Agency. In this variant, risk filtering takes place through the preferred status of the Debt Agency and the diversification of the sovereign debts portfolio. The points of strength of this second option are the issuing of a safe asset without any need for tranching, as in the first variant, but relying not on capital endowment but on the preferred credit status of the Debt Agency and on the diversification of the underlying portfolio. The second weakness is that the preferred status reintroduces the juniority effect on the portion of the debt which is not included in the DA.

3. In the third variant, the Debt Agency would issue a safe asset backed by an international diversified portfolio, not restricted to sovereign debts. As in the first case, the Debt Agency should be adequately capitalized. Strengths and weaknesses of this proposal are consequently similar to those of the first option. In this case, diversification, not being linked to European sovereign debts, could be more effective. However, the Eurozone countries would not get any direct risk filtering benefit on their public debt.

In the fourth type, safe assets could be a bond issued by an Eurozone budget (Ubide 2015; Zettelmeyer 2017). In this case, the installments of the safe asset would be financed through a dedicated European tax or, in any case, from previously identified funds. The main strengths of the proposal would be the Eurozone's guarantee of repaying the debt issued in addition to having created an initial form of common European fiscal policy. The main weakness is that current political conditions would allow the issuance of an initially very limited amount of safe assets, given the total mutualization of the risk and the initial limitedness of the common tax revenues.

As we can see from this brief review, the "safe asset puzzle" seems not to admit a straightforward synthesis. In each "ideal type" the risk remains of a cleavage between the sovereign debts made safe (either by common operation of pooling and tranching, unless at the price of the provision of high public guarantees) and the remaining debts, made potentially more uncertain than before.

So, in a sense, the main goal which is common to all tranching proposals, namely risk filtering, tends to transform itself surreptitiously into the goal of a risk translation, to be overpaid by the more indebted nations. But not only this. 
As we highlighted at the beginning of this section, the shortage of safe assets in the Eurozone and the lack of a true European bond are the two facets of the same problem. This means that the problems arising for the junior tranches proposed or, more in general, for that part of the sovereign Eurozone debts which are perceived as "junior", can pose a problem also concerning the status of the safe asset. An increase of the default risk of a country, due to an increase in the volatility of its "unsafe" part of debt can eventually undermine the safety of the underlying portfolio of a safe asset issuer.

Moreover, if the safe asset is backed by a diversified portfolio of sovereign debts and, at the same time, national public debt securities are traded on the markets, it would be very difficult to avoid a flight-to-quality dynamic during turmoil.

One can then argue in favor of less "market-centered" forms of safe asset issuing. But this option introduces the problem of the nature as well as of the quantitative level of the public guarantees. The adequacy of a capital endowment depends also on the risk that are actually transferred to the agency charged with the issuing of the safe asset, i.e. it depends on the efficiency with which it operates the risk filtering. The capital endowment could then involve some necessary form of mutualization, which is a major political problem in today Eurozone. Therefore, the size of the public guarantees is a critical variable that creates a trade-off. On the one hand, we have the "market-centered" proposals, which were born due to the lack of agreement between the various countries of the euro area with respect to the high degree of risk socialization. On the other hand, we have "public-guarantees" solutions, according to which it is not possible to obtain a real safe asset without any form of risk sharing.

The question is then: at what conditions a "safe agency" can be conceived issuing an adequate quantity of safe assets

1. without requiring any form of preferred clause

2. without requiring any form of tranching

3. without requiring any form of mutualization

4. with a capital endowment minimizing public guarantees in order to be financially sustainable and politically feasible?

This is what we intend to explore in the next section.

\section{Debt Agency}

\subsection{Institutional framework}

An adequate institutional vehicle at Eurozone level (to be established or already existing) is identified, with Eurozone Member States (MS) as main shareholders. The common ownership could be founded upon the paragraph 2 of article 122 of TFUE. It could initially rely on an "enhanced cooperation vehicle" (art. 20 
TUE and 326 et seq. TFUE). This vehicle could employ the resources already conferred to the ESM (Perillo 2020). Let us call it European Debt Agency (DA).

Based on an adequate solvency capital endowment, the DA

1. collects liquid funds on markets by issuing plain vanilla bonds with finite maturity,

2. uses these funds to finance MSs with infinite maturity loans.

The DA does not purchase outstanding debt, but only MSs' new or expiring debt, buying it on the primary market, according to predetermined price formulas.

Being perpetual, the share of debt financed through the DA is structurally hedged from liquidity risk. Indeed, the main purpose of this operation framework consists in "immunizing" MSs' fiscal budgets from market liquidity risk.

For this reason, as well as for the presence of adequate solvency capital endowment, based on an insurance scheme, no seniority clause is necessary to support the creditworthiness of the DA, which avoids a dualistic situation between debt in the DA and floating debt on the markets, i.e. it avoids a surreptitious resurgence of the "cleavage effect" caused by tranching (see section 2).

The DA receives from each MS an annual installment calculated considering only MS' fundamental risk, since the DA filters the market liquidity spread risk. The overall flow of installments, net of legal provisions, allows then the DA to remunerate its bondholders at a rate which is in line with its high rating, and most of all with the ECB long term rate, since the ECB will stabilize the whole DA mechanism by directly buying its bonds in order to align their yield to that rate and which therefore will be lower than the average of the fundamental cost of each MS (cost of the underlying portfolio). The DA thus reaches its financial equilibrium at more advantageous conditions than any portfolio manager on the market.

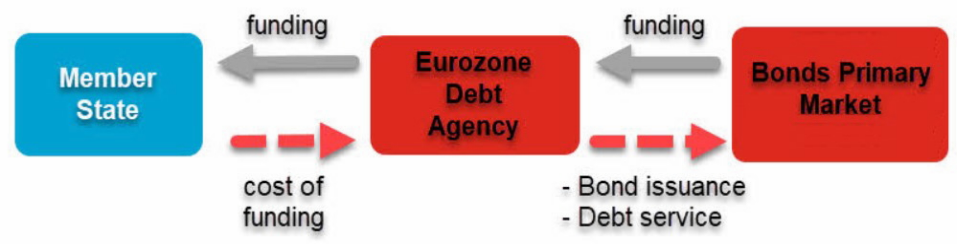

Figure 2: Financial flows

We have mentioned that this proposal for the debt agency does not require recognition of a "preferred creditor" status since the "safety" of the vehicle is obtained by means of its very intrinsic architecture. Nonetheless, this framework should be accompanied by adequate features such as: 
1. high level of governance and independence of the agency in order to manage conflicts of interest;

2. adherence to the supervision standards set out for the SSM (Single Supervisory Mechanism) and the European prudential regulation;

3. ex-ante budget control rules for MSs and the prescription of suitable recovery plans for the management of the debt conferred to the agency in case of forbearance.

To sum up: by acting as a "protective gap" between the issuing MSs and the markets, the DA allows

1. MSs to pay an installment which is linked to their fundamental risk and only to that;

2. markets to dispose of an asset filtered from liquidity risk, hence more secure than any possible portfolio;

3. systemic financial actors to overcome the safe asset shortage which makes it difficult for them to manage their business cycle (for banks, the liquidity cycle; for insures and pension funds, the management of guarantees on return on investment);

4. the Eurozone to behave as a homogeneous space, issuing a common bond which does not need any kind of mutualization;

5. to progressively dissolve the "doom loop" that at present links the solvency of MSs to that of the respective banking systems, and vice versa.

In other terms: the DA's bond does not imply mutualization, and it enjoys a "pooling effect" that structurally lowers its risk. The DA thus acts as a "synthetic treasury" that issues a common bond that can be bought by the ECB without infringing its commitment not to "favor" any MS, which is the raison d'etre of the capital key. Figure 2 above gives a schematic representation of the relationships among MSs, DA and markets.

\subsection{General settings}

The funding cost structure weighing on a single MS is computed by considering its specific "fundamental risk", which obviously is the result of many factors, such as the debt-to-GDP ratio, the current deficit and all the other macroeconomic variables that influence MSs' credit rating. By leveraging on the potential irredeemable nature of sovereign debts, we propose to price the overall cost throughout an amortizing scheme according to which every single MS pays for an infinite period of time only a risk-adjusted interest. There is in fact no conclusive economic reason why a MS should redeem its debt with the DA at fixed date, whereas the DA has the possibility to manage its own debt renewals and 
deadlines autonomously by resorting to new debt collected in the market and financed at lower costs, thanks to its higher credit standing.

In the following sections, we consider a credit portfolio $\mathbf{d}^{T}=\left[d_{1}, \ldots, d_{j}, \ldots d_{n}\right]$ of total holding $T D=\sum_{j=1, \ldots, n} d_{j}$, held by the DA and diversified in $n$ different rating grade classes of obligors, each class labeled with its rating grade $j$ and with total exposure $d_{j}$. Note that the last $n$-th class stands for a default absorbing status and has at the inception $d_{n}=0$.

In projecting portfolio expected values, we assume a portfolio with infinite granularity of obligors in each rating grade class, such that the exposure towards each single obligor of rating grade $j$ be infinitesimal. Neglecting DA operating expenses, we will highlight three distinctive aspects of the agency framework hereby proposed:

1. the pricing of the fundamental risk for each rating grade class, following an irredeemable amortization scheme;

2. the DA intertemporal equilibrium;

3. the DA required risk-capital for solvency purposes in the form of an insurance scheme.

\subsection{Fundamental pricing}

To measure the credit-standing migration risk to which each class is exposed, we propose a methodology to calculate perpetual annuities based on a throughthe-cycle transition matrix. Given a point-in-time transition matrix $T M_{t}$ at time $t$, its generic element $a_{j i}$ represents the annual probability of an obligor of rating grade $j$ in year $t$ to pass to a rating grade $i$ in the following year. The matrix has dimension $n \times n$ and the elements of row $j, a_{j 1}, \ldots, a_{j n}$ must sum to unity, since every obligor with rating $j$ will certainly be assigned to some rating grade $i \in\{1, \ldots, j, \ldots n\}$ from year $t$ to $t+1$, including the case of being reassigned to the same rating $j$. As a convention, the rows and the columns of $T M_{t}$ are ordered according to safety grades, from the safest (label AAA) to the default (label D: default state). Following the standard diagonalization method for square matrices, we assume that the $T M_{t}$ matrix can be decomposed in a $Q$ matrix and a $L_{t}$ diagonal matrix such as:

$$
T M_{t}=Q L_{t} Q^{-1}
$$

The $L_{t}$ matrix depends on $t$ and shows correlations with the business cycle ${ }^{1}$ in its elements $l_{i j}(t)$. In particular we assume that these values depend on shocks of the business cycle according to the following generalized logistic function:

$$
l_{j}(y)=\frac{\theta_{j 1}}{\left(1+\theta_{j 2} \exp \left(\theta_{j 3} y\right)\right)}
$$

\footnotetext{
${ }^{1}$ For sake of simplicity, our analysis does not consider real growth, but this does not hamper the generality of our main results.
} 
with $y$ a zero average business cycle shock and parameters $\theta_{j h}$, calibrated such that the expected value of the $l_{i j}$ is $E\left(l_{i j}\right)=\lambda_{i j}$, with $\lambda_{i j}$ being the element $i j$ of the eigenvalues diagonal matrix $\Lambda$ in the decomposition:

$$
T T C=Q \Lambda Q^{-1}
$$

The decomposition being unique unless linear transformations, $Q$ represents the eigenvectors matrix of the above linear functional.

Proposition 1 The matrix TTC, interpreted as a through-the-cycle matrix, is the expectation of the stochastic process $T M_{t}$.

Proof. Take the expectation of the process $T M_{t}$ and substitute $E\left(l_{i j}\right)$ with $\lambda_{i j}$ :

$$
\begin{aligned}
T T C & =E\left(T M_{t}\right) \\
& =E\left(Q L_{t} Q^{-1}\right) \\
& =Q E\left(L_{t}\right) Q^{-1} \\
& =Q \Lambda Q^{-1}
\end{aligned}
$$

Following this model, the expected cumulative default probability in the interval $[t, t+m]$ is the linear operator given by:

$$
E[\mathbf{c d p}(t+m)-\mathbf{c d p}(t)]=Q\left(\Lambda^{t+m}-\Lambda^{t}\right) Q^{-1} \mathbf{v}
$$

where $\operatorname{cdp}(t)$ is an $n$-components stochastic process, the $j$-th element of which, $c d p_{\mathbf{j}}(t)$, represents the cumulative default probability that an obligor of rating grade class $j=1, \ldots, n$ will have defaulted by time $t$, with $\mathbf{c d p}(0)=0$ and $\mathbf{v}$ a null vector apart its last element equal to 1 .

Proof. Assuming independence between matrices $L_{v} \perp L_{u}$ with $v, u \in[0, t]$, $v \neq u$, we have:

$$
\begin{aligned}
E[\mathbf{c d p}(t)] & =E\left[\prod_{\tau=0, \ldots t} T M_{\tau}\right] \mathbf{v}=E\left[\prod_{\tau=0, \ldots t} Q L_{\tau} Q^{-1}\right] \mathbf{v} \\
& =Q E\left[\prod_{\tau=0, \ldots t} L_{\tau}\right] Q^{-1} \mathbf{v}=Q E\left[\prod_{\tau=0, \ldots t} L_{\tau}\right] Q^{-1} \mathbf{v} \\
& =Q\left[\prod_{\tau=0, \ldots t} E\left(L_{\tau}\right)\right] Q^{-1} \mathbf{v}=Q\left[\prod_{\tau=0, \ldots t} \Lambda\right] Q^{-1} \mathbf{v} \\
& =Q \Lambda^{t} Q^{-1} \mathbf{v}
\end{aligned}
$$

Hence we can write:

$$
\begin{aligned}
E[\mathbf{c d p}(t+m)-\mathbf{c d p}(t)] & =E[\operatorname{cdp}(t+m)-\mathbf{c d p}(t)] \\
& =E[\operatorname{cdp}(t+m)]-E[\mathbf{c d p}(t)] \\
& =\left(Q \Lambda^{t+m} Q^{-1}-Q \Lambda^{t} Q^{-1}\right) \mathbf{v} \\
& =-Q\left(\Lambda^{t+m}-\Lambda^{t}\right) Q^{-1} \mathbf{v}
\end{aligned}
$$


Since our primary goal is to price the fundamental risk of each obligor class with rating grade $j$, from here on we will use of the matrix TTC as the reference risk metric to calculate obligors' default probabilities under expectations. We assume that the valuation date occurs at time $t=0$ unless otherwise specified, which simplifies our notation, but all the following mathematical expressions can be easily rephrased in order to include index $t_{0}$ to fix any time reference in the interval $[0, t]$.

Under the condition (4), the survival probability vector in the interval $\tau \in$ $[0, t]$ can be written as:

$$
\mathbf{s p}(0, t)=E[\mathbf{1}-\mathbf{c d p}(t)]=\mathbf{1}-Q \Lambda^{t} Q^{-1} \mathbf{v}
$$

where $\mathbf{1}$ is the unit vector. The $n$-th element of vector sp $(0, t)$ corresponding to the default state is null.

The expected present value of a vector of unitary annuity maturing at time $t$ can be written as:

$$
\mathbf{a}(0, t)=\sum_{\tau=0,1, \ldots t} \frac{1}{(1+\pi)^{\tau}} \mathbf{s p}(0, \tau)
$$

where $\pi$ represents a common appropriate financial discount rate ${ }^{2}$. Notice that the components of vector $\mathbf{a}(0, t)$ are ordered decreasingly, with the highest rating grades corresponding to higher annuity values since the present value of a unitary annuity is proportional to the survival probability of the corresponding rating grade class and a null value for the vector last component. Using the expression of $\mathbf{s p}(t)$ in eq. (5), we can rewrite:

$$
\mathbf{a}(0, t)=\sum_{\tau=0,1, \ldots t}\left[\frac{1}{(1+\pi)^{\tau}}\left(\mathbf{1}-Q \Lambda^{\tau} Q^{-1} \mathbf{v}\right)\right]
$$

Now, by letting $\alpha=1 /(1+\pi)$ and $\beta_{j}=\lambda_{j} /(1+\pi)$, with $\lambda_{j}$ the $\mathrm{j}$-th eigenvalue in matrix $\Lambda$, the above expression can be written:

$$
\mathbf{a}(0, t)=\alpha \frac{1-\alpha^{t}}{1-\alpha} \mathbf{1}-Q B Q^{-1} \mathbf{v}
$$

where $B$ is a diagonal matrix whose $j$-th element is $b_{j}=\beta_{j} \frac{1-\beta_{j}^{t}}{1-\beta_{j}}$. Since the terms in $\Lambda$ are $\lambda_{j} \leq 1$, it follows $\alpha, \beta_{j} \in(0,1)$. By taking the limit for $t \rightarrow \infty$ we obtain the following perpetual annuity formula:

$$
\mathbf{a}(0)=\lim _{t \rightarrow \infty} \mathbf{a}(0, t)=\frac{\alpha}{1-\alpha} \mathbf{1}-Q B^{\prime} Q^{-1} \mathbf{v}
$$

\footnotetext{
${ }^{2}$ For simplicity's sake, it has been assumed that the purely financial rate $\pi$ does not exhibit a term structure. This hypothesis represents a mere simplification for calculation purposes which can easily be removed.
} 
with $B \prime$ a diagonal matrix with $j$-th element $b_{j}^{\prime}=\frac{\beta_{j}}{1-\beta_{j}}$. The vector $\mathbf{a}(0)$ in the eq. (6) represents expected present values at $t=0$ of an annuity of an irredeemable mortgage paid out by each obligor according to its rating grade. In order to consider the possibility to recover part of the credit in case an obligor defaults, we should adjust the value of a $\mathbf{a}(0)$ accordingly. To this end, eq. (6) should be modified to take into account this effect. Introducing the loss-given-default (LGD), $(1-r r)$, and let be $r r$ the recovery rate that will be recovered by the DA. ${ }^{3}$ The vector of expected values of the recovery rates, for the different rating grades, by time $t$ is:

$$
\begin{aligned}
\mathbf{r}(0, t) & =E\left[\operatorname{rr} \sum_{\tau=0,1, \ldots t} \frac{1}{(1+\pi)^{\tau}}[\mathbf{c d p}(\tau)-\mathbf{c d p}(\tau-1)]\right] \\
& =r r \sum_{\tau=0,1, \ldots t} \frac{1}{(1+\pi)^{\tau}}[E(\operatorname{cdp}(\tau))-E(\mathbf{c d p}(\tau-1))]
\end{aligned}
$$

where the summation considers the probabilities that a failure occurs at each $\tau$ in $[0, t]$. A closed form for the expected recovery rate can be obtained by taking the limit of matrix $\Lambda^{t}$ for $t \rightarrow \infty$. Substituting for $E(\operatorname{cdp}(\tau))$ and recalling that $\Lambda$ is a diagonal matrix of constant terms we obtain:

$$
\begin{aligned}
\mathbf{r}(0, t) & =\operatorname{rr}\left[\sum_{\tau=0,1, \ldots t} \frac{1}{(1+\pi)^{\tau}} Q \Lambda^{\tau} Q^{-1}-\frac{1}{(1+\pi)^{\tau}} Q \Lambda^{\tau} \Lambda^{-1} Q^{-1}\right] \mathbf{v} \\
& =\operatorname{rr} Q\left[\sum_{\tau=0,1, \ldots t} \frac{1}{(1+\pi)^{\tau}} \Lambda^{\tau}\left(I-\Lambda^{-1}\right)\right] Q^{-1} \mathbf{v} \\
& =\operatorname{rr} Q\left[\left(I-\Lambda^{-1}\right) \sum_{\tau=0,1, \ldots t} \frac{1}{(1+\pi)^{\tau}} \Lambda^{\tau}\right] Q^{-1} \mathbf{v}
\end{aligned}
$$

By taking the limit for $\tau \rightarrow \infty$ we get the following formula for the expected recovery rate:

$$
\mathbf{r}(0)=\operatorname{rr} Q\left[\left(I-\Lambda^{-1}\right) B^{\prime}\right] Q^{-1} \mathbf{v}
$$

Following a unitary-payment perpetual amortizing scheme and allowing for partial recovery of funds in case of default, the value of an expected positive exposure $\tilde{a}_{j}$ must always satisfy the equivalence $\tilde{a}_{j}\left(1-r_{j}\right)=a_{j}$, where $r_{j}<1$ is $j$-th element of the vector $\mathbf{r}_{0}$. Taking this in mind, the final expectation of a unitary perpetual annuity value at time $t=0$ calculated for each obligor according to its rating grade $j$ is then:

\footnotetext{
${ }^{3}$ The LGD parameter should be identified for each Member State in order to take into account its specific risk. Since our ultimate purpose is to provide an exemplification of a possible DA architecture based on an irreedimable cost configuration, in our calculations we assume a uniform LGD value for all MSs.
} 


$$
\tilde{a}_{j}=\frac{a_{j}}{1-r_{j}}
$$

The vector $\tilde{\mathbf{a}}(0)$, whose elements are the values $\tilde{a}_{j}$, can be interpreted as a set of perpetual annuities based on fundamental risk metrics inherent to obligors labelled with specific rating grades. Equation (9) allows to establish conditions for credit portfolio pricing and DA financial equilibrium, once the functional form for the portfolio default probability $c d p_{W}(t)$ for $t \geqq 0$ has been specified.

Proposition 2 Given the initial portfolio asset allocation $\mathbf{w}_{0}^{T}=\left[w_{1}, \ldots, w_{j}, \ldots w_{n}\right]$, with $w_{j}=d_{j} / T D$, the DA will price the risks for $t \geqq 0$ using the portfolio expected default probabilities $E\left(c d p_{W}(t)\right)=\mathbf{w}_{0}^{T} Q \Lambda^{t} Q^{-1} v$ and setting the overall annual payments $I_{W}(t)$ at time $t=0$ such that its financial equilibrium holds in expectations:

$$
T D=I_{W}(0) \tilde{a}_{W}(0)=I_{W}(0) \mathbf{w}_{0}^{T} \tilde{\mathbf{a}}(0)=I_{W}(0) \sum_{j=1, \ldots, n} w_{j} \tilde{a}_{j}
$$

Proof. Let be $\tilde{a}_{W}(0)$ such that $\tilde{a}_{W}(0)\left(1-\sum_{j=1, \ldots, n} z_{j} r_{j}\right)=\sum_{j=1, \ldots, n} w_{j} a_{j}$, with $\sum_{j=1, \ldots, n} z_{j}=1$, we have:

$$
\begin{aligned}
\tilde{a}_{W}(0)\left(\sum_{j=1, \ldots, n} z_{j}-\sum_{j=1, \ldots, n} z_{j} r_{j}\right) & =\sum_{j=1, \ldots, n} w_{j} a_{j} \\
\sum_{j=1, \ldots, n} z_{j} \tilde{a}_{W}(0)\left(1-r_{j}\right) & =\sum_{j=1, \ldots, n} w_{j} a_{j}
\end{aligned}
$$

A non trivial solution of this equation is $z_{j} \tilde{a}_{W}(0)=w_{j} \frac{a_{j}}{\left(1-r_{j}\right)}=w_{j} \tilde{a}_{j}$, for $j=1, \ldots, n$. Summing up for $j$, we obtain $\tilde{a}_{W}(0) \sum_{j=1, \ldots, n} z_{j}=\sum_{j=1, \ldots, n} w_{j} \tilde{a}_{j}$, i.e. $\tilde{a}_{W}(0)=\sum_{j=1, \ldots, n} w_{j} \tilde{a}_{j}$. It also follows that $z_{j}$ is a linear combination such that:

$$
z_{j}=\frac{w_{j} \tilde{a}_{j}}{\sum_{j=1, \ldots, n} w_{j} \tilde{a}_{j}}
$$

However, the solution $I_{W}(0)$ is not the only one solving the equation (10). In fact, letting the vector $\mathbf{c}_{t}^{T}=\left[c_{1}, c_{2}, \ldots, c_{j}, \ldots c_{n}\right]$ represent the overall payments due at time $t=0$ by each rating grade class $j$, the financial equilibrium requires that the sum of their expected value, $\mathbf{c}^{T} \mathbf{a}(0)$, and the overall expected recovery value, $\mathbf{d}^{T} \mathbf{r}(0)$, be equal to the total credit portfolio holding $T D$ :

$$
\begin{aligned}
T D & =\sum_{j=1, \ldots, n} d_{j}=\mathbf{c}^{T} \mathbf{a}(0)+\mathbf{d}^{T} \mathbf{r}(0) \\
& =\sum_{j=1, \ldots, n} c_{j} a_{j}+\mathbf{d}^{T} \mathbf{r}(0)
\end{aligned}
$$


Solving for each $c_{j}$ we obtain:

$$
c_{j}=\frac{\sum_{i=1}^{n} d_{i}\left(1-r_{i}\right)}{a_{j}}-\frac{\sum_{i \neq j}^{n} c_{i} a_{i}}{a_{j}}
$$

or

$$
c_{j} a_{j}=\sum_{i=1}^{n} d_{i}\left(1-r_{i}\right)-c_{1} a_{1}-\ldots-c_{j-1} a_{j-1}-c_{j+1} a_{j+1}-\ldots-c_{n-1} a_{n-1}
$$

The solution value for $c_{j}(11)$ can be found for infinite arbitrary combinations of the other $c_{i}, i \neq j$. General financial criteria of course apply to determine "admissible" values to the $c_{j}$. A special solution, that we call here idiomatic fundamental pricing solution, consists in relating the payments of the $j$-th class to the corresponding debt level and riskiness:

$$
c_{f j}=\frac{d_{j}\left(1-r_{j}\right)}{a_{j}}=\frac{d_{j}}{\tilde{a}_{j}}
$$

The specific feature of this solution is that each obligor pays for the risk inherent to the specific rating grade class it is assigned to, without any form of solidarity or mutuality among obligors of different classes.

Proposition 3 The idiomatic fundamental pricing solution solves the eq. (11)

Proof. The fundamental solution implies:

$$
\begin{aligned}
T D & =\sum_{j=1, \ldots, n} \frac{d_{j}\left(1-r_{j}\right)}{a_{j}} a_{j}+\mathbf{d}^{T} \mathbf{r}_{0} \\
& =T D
\end{aligned}
$$

Nevertheless, the solution (12) does not price in line to portfolio expected default probabilities, giving rise to the following straightforward proposition.

Proposition 4 Be $I_{F}(0)=\sum_{j=1, \ldots, n} c_{f j}=\sum_{j=1, \ldots, n} \frac{d_{j}}{\tilde{a}_{j}}$, if we price the portfolio $\mathbf{d}^{T}$ using portfolio expected default probabilities, $E\left(c d p_{W}(t)\right)=\mathbf{w}_{0}^{T} Q \Lambda^{t} Q^{-1} \mathbf{v}$ for $t>0$, the total payments at $t=0$ are such that $I_{F}(0)>I_{W}(0)$. 
Proof. In the following we demonstrate that $\frac{I_{F}(0)}{I_{W}(0)} \geqq 1$.

$$
\begin{aligned}
\frac{I_{F}(0)}{I_{W}(0)} & =\left(\sum_{j=1, \ldots, n} \frac{d_{j}}{\tilde{a}_{j}}\right) /\left(\frac{T D}{\sum_{i=1, \ldots, n} w_{i} \tilde{a}_{i}}\right) \\
& =\left(\sum_{j=1, \ldots, n} \frac{d_{j} / T D}{\tilde{a}_{j}}\right)\left(\sum_{i=1, \ldots, n} w_{i} \tilde{a}_{i}\right) \\
& =\left(\sum_{j=1, \ldots, n} \frac{w_{j}}{\tilde{a}_{j}}\right)\left(\sum_{i=1, \ldots, n} w_{i} \tilde{a}_{i}\right) \\
& =\sum_{j=1, \ldots, n} \frac{w_{j} \sum_{i=1, \ldots, n} w_{i} \tilde{a}_{i}}{\tilde{a}_{j}} \\
& =\sum_{j=1, \ldots, n} \frac{\sum_{i=1, \ldots, n} w_{j} w_{i} \tilde{a}_{i}}{\tilde{a}_{j}}
\end{aligned}
$$

Let's order the $\tilde{a}_{j}$ by rating grades $\tilde{a}_{1}>\tilde{a}_{2}>\ldots>\tilde{a}_{n}$, so that on-diagonal and lower-triangle-off-diagonal elements are $0<w_{j} w_{i}<1$ with $j \geqq j$, while upper-triangle-off-diagonal elements are such that $w_{j} w_{i}\left(\tilde{a}_{i} / \tilde{a}_{j}+\tilde{a}_{j} / \tilde{a}_{i}-1\right) \geqq 0$, for $i<j$, or $w_{j} w_{i}\left(\tilde{a}_{i} / \tilde{a}_{j}+\tilde{a}_{j} / \tilde{a}_{i}\right) \geqq w_{j} w_{i}$, which is surely true since either $\tilde{a}_{i} / \tilde{a}_{j}>1$ or $\tilde{a}_{j} / \tilde{a}_{i}>1$. Then it follows that $\frac{I_{F}(0)}{I_{W}(0)} \geqq 1$ and $I_{F}(0) \geqq I_{W}(0)$.

Proposition 5 If for $t=0$ the DA computes the fair value of the portfolio pv(0) using portfolio default probabilities but charges obligors individually by using the idiomatic fundamental pricing formula (12), such that pv(0) $=I_{F}(0) \tilde{a}_{W}(0)$, then:

- the portfolio fair value will be greater than the TD, thus generating for the agency a positive economic value of equity eve $(0)=p v(0)-T D$

$$
p v(0) \geqq T D
$$

- the economic value of equity can be remunerated at a positive interest rate:

$$
f c \leqq\left[\left(I_{F}(0)-I_{W}(0)\right) / \text { eve }_{0}\right]
$$

Proof. from equation (10) it follows that

$$
p v(0)=I_{F}(0) \mathbf{w}_{0}^{T} \tilde{\mathbf{a}}_{\mathbf{0}} \geqq I_{W}(0) \mathbf{w}_{0}^{T} \tilde{\mathbf{a}}_{0}=T D
$$


Remark 6 The total payment $I_{W}(0)$ obtained under the equilibrium condition (10) is structurally lower than the amount due in the idiomatic fundamental pricing configuration. This is attributable to a "pooling effect", i.e., in our case, to the fact that, within a portfolio approach, the transition probabilities among rating grade classes entail a risk mitigation benefit, since they imply, in each year of observations, potential improvements in the rating of the worst classes.

The proposition (5) is relevant because it shows that the DA generates value for potential investors, collecting additional risk capital that can be used for solvency purposes. Also relevant is the question of overall cost distribution among obligors. Herein we only want outline that the overall cost of the portfolio obviously depends on the cost distribution rule that we adopt to charge each rating grade class.

Proposition 7 Under the pricing rule defined by (10), if we charge each rating grade class $j$ in proportion to its debt, i.e. using the weight $w j=d j / T D$, then we equalize the price of risk uniformly, thus ending up mutualizing part of the debts among classes.

Proof. Under (10) set the portfolio unit cost of the risk equal $u c r_{W}=I_{W}(0) / T D$. Now consider the idiomatic fundamental risk pricing rule under (12) and set the unit cost of the risk for the rating grade class $j$ equal $u c r_{j}=c_{f j} / d_{j}$. For an obligor $i$ of rating grade $j$ and nominal debt $\delta_{j i}$ if $u c r_{j}>u c r_{W}$ its equivalent nominal debt $\delta_{j i}^{\prime}$ is

$$
\delta_{j i}^{\prime}<\frac{u c r_{W}}{u c r_{j}} \delta_{j i}
$$

\subsection{DA's intertemporal equilibrium}

Until now, we have supposed that the DA 1) determines its periodic cash flow according to an irredeemable amortization scheme, 2) prices risks using the metrics (3), and that 3 ) no extra provisions or capital charges for unexpected losses or other risks are needed (in the next subsection we will challenge and overcome this assumption). Since at time $t \geqq 0$ the proposition (3) always holds true, we illustrate the financial equilibrium of the DA by using the pricing formula given by the eq. (10) and we leverage on a fundamental characterization of our agency institutional framework, which will be fully explained in the next section. Given the agency asset allocation, $\mathbf{w}_{t}^{T}=\left[w_{1}, \ldots, w_{j}, \ldots w_{n}\right]$, and the portfolio intertemporal default probability $c d p_{W}(t)$ up to time $t$, we characterize proportion of defaults at portfolio level, $w_{n}$, as represented by the following process:

$$
w_{n}=E\left[c d p_{W}(t)\right]=\mathbf{w}_{t-1}^{T} Q \Lambda Q^{-1} \mathbf{v}
$$

with $\sum_{j=1, \ldots n} w_{j}=1$ and $\mathbf{v}$ a null vector apart its last element equal to 1 . 
Remark 8 The formula (13) states that, although the asset allocation can evolve considering erratic rating grade migration and that the non-default classes can diverge considerably from their expected value, on the contrary, the default class always must evolve according to its expected value. In the next section, we will show that this setting is consistent with the particular meaning of default that works effectively for MSs in the institutional context of the Eurozone. This device allows to cumulate the share of debtors that have defaulted at every time $t$, which is necessary to correctly calculate the agency intertemporal equilibrium. Note that future portfolio default probabilities will be the result of actual rating grade migrations .

In developing the agency intertemporal equilibrium we resort to the following statements:

1. the appropriate average loss-given-default (LGD) rate is $\left(1-r r_{W}\right)$, with $r r_{W}$ representing percentage of nominal debt recovered in case of default (i.e. the portfolio recovery rate)

2. the agency annual discount rate used to compute present values is $\pi_{t}$

3. the agency reserves deposit is remunerated at an annualized interest rate $\pi_{t}^{\prime}$ set by the Central Bank, which is conceived as the long term equilibrium rate of its monetary policy

4. the agency holding equals $T D=\sum_{j} d_{j}$ and it is rolled over by an infinite span of time, issuing and renewing at pair indexed bonds of unitary maturity (e.g. 1 year) of overall face value equal $T D$

5. the agency's funding cost $F C=\pi_{t}^{\prime \prime} T D$ being determined using an annual interest rate of $\pi_{t}^{\prime \prime}$.

If we suppose that the DA can reprice obligors' funding costs by using the eq. (10), then its net exposure at time $t$ is subject to the following constraint, which has to be solved for $I_{W}(t)$ :

$$
T D-r s(t)=p v_{W}(t)=I_{W}(t) \tilde{a}_{W}(t)=I_{W}(t) \mathbf{w}_{t}^{T} \tilde{\mathbf{a}}_{t}
$$

where $p v_{W}(t)$ is the present value of future cash flow and $r s(t)$ is the total cumulated reserve deposit at the Central Bank, given by:

$$
\begin{aligned}
r s(t) & =r s(t-1)\left(1+\pi^{\prime}\right)+I_{W}(t-1)\left[1-\left(c d p_{W}(t)-c d p_{W}(t-1)\right)\right]+ \\
& +r r_{W} T D\left(c d p_{W}(t)-c d p_{W}(t-1)\right)-F C
\end{aligned}
$$

with $r s(0)=0$. Given the portfolio share of defaulted obligors $\left(c d p_{W}(t)-\right.$ $\left.c d p_{W}(t-1)\right)$ in the interval $[t-1, t], r r_{W} T D\left(c d p_{W}(t)-c d p_{W}(t-1)\right)$ represents the cash inflow due to recovery from defaulted obligors. Note that $r s(t)$ is a stochastic realization of $c d p_{W}(\tau)$ for $\tau \leqq t$, which is known at time $t$. This 
equilibrium implies that in the case of adverse rating grade migrations in the interval $[t-1 ; t]$, the surviving obligors will bear a greater cost for $I_{W}(t)$ in order to assure the agency equilibrium over time (14).

Considering the three mentioned rates $\pi_{t}, \pi_{t}^{\prime}$ and $\pi_{t}^{\prime \prime}$, it is worth observing that:

1. they are expectations conditional on information available at time $t$;

2. by institutional design, the agency will fix the $\pi_{t}$ rate equal to the Central Bank's long-term rate $\pi_{t}^{\prime}$;

3. by design, also the agency issuances are indexed to $\pi_{t}^{\prime}$;

4. the rate $\pi_{t}^{\prime \prime}$ will always be such that $\pi_{t}^{\prime \prime} \leq \pi_{t}^{\prime}$, since by design the Central Bank always buys the residual issuance in order to ensure the alignment of the yield to $\pi_{t}^{\prime}$ (see section 3 );

Proposition 9 For $t \geq 0$, if $\pi_{t}=\pi_{t}^{\prime}=\pi_{t}^{\prime \prime}$ and the agency reprices the obligors' cost at every $t$ using eq. (10), then $T D=p v_{W}(t)+r s(t)$ : the agency balance sheet asset-side always equates the liability-side, and the agency equilibrium is assured over time.

Proof. The proposition follows directly from eq. (14), which states that for the portfolio fair value at time $t$ we have $p v_{W}(t)=I_{W}(t) \tilde{a}_{W}(t)$, then:

$$
p v_{W}(t)+r s(t)=T D
$$

with $p v_{W}(0)=T D$

Remark 10 Note that, for $t \longrightarrow \infty$, since $p v_{W}(t) \longrightarrow 0$ then $r s(t) \longrightarrow T D$ and the agency will have piled up enough reserves to repay its bonds nominal value.

Proposition 11 For $t \geq 1$, if $\pi_{t}=\pi_{t}^{\prime}=\pi_{t}^{\prime \prime}$ then returns from the DA's asset side are expected to remunerate the liability side, i.e. $\left[p v_{W}(t)+r s(t)\right](1+\pi)=$ $T D+F C$ : 
Proof. From the previous proposition, we obtain

$$
\begin{aligned}
\left(p v_{W}(t)+r s(t)\right)\left(1+\pi_{t}\right) & =\left(1+\pi_{t}\right) E\left\{\sum_{\tau=t}^{\infty} I_{W}(t) \frac{\left(1-c d p_{W}(\tau+1)\right)}{\left(1+\pi_{t}\right)^{(\tau+1-t)}}\right\}+ \\
& +\left(1+\pi_{t}\right) E\left\{r r_{W} T D \sum_{\tau=t}^{\infty} \frac{\left(c d p_{W}(\tau+1)-c d p_{W}(\tau)\right)}{\left(1+\pi_{t}\right)^{\tau+1-t}}\right\}+ \\
& +r s(t+1)-E\left\{I_{W}(t)\left(1-c d p_{W}(t+1)\right)\right\}- \\
& -E\left\{r r_{W} T D\left(c d p_{W}(t+1)-c d p_{W}(t)\right)-F C\right\} \\
& =E\left\{\sum_{\tau=t+1}^{\infty} I_{W}(t) \frac{\left(1-c d p_{W}(\tau+1)\right)}{\left(1+\pi_{t}\right)^{(\tau+1-t)}}\right\}+ \\
& +E\left\{r r_{W} T D \sum_{\tau=t+1}^{\infty} \frac{\left(c d p_{W}(\tau+1-t)-c d p_{W}(\tau-t)\right)}{\left(1+\pi_{t}\right)^{\tau+1-t}}\right\}+F C \\
& =p v_{W}(t+1)+r s(t+1)+F C=T D+F C
\end{aligned}
$$

Where $p v_{W}(t+1)$ and $r s(t+1)$ represent expectations for $t+1$ as valued in

$t$.

We have shown that, since the DA is able to align:

1. interest rates used to compute revenues and present values

2. returns on reserves in form of deposits at the Central Bank

3. the cost of funding,

then, by the propositions (6) and (7) the DA will always be able, in expectation, to back liabilities with the fair value of its assets. This entails that, in an "arm's length transaction", as prescribed by standards such as Solvency II and Basel III, the agency will always be able to repay its overall debt of $T D$ at any time it would be requested.

\subsection{Solvency capital}

So far, we have considered that the DA prices its own risks using the expected default probabilities term-structure with infinite granularity of obligors in each rating grade of the underlying portfolio.

Within a "closed portfolio" irredeemable framework, default's outcomes deal only with the "when" they occur, since the portfolio cumulative default probability over an infinite time span always equates 1 , given that TTC matrix is recursive and has one absorbing state, coinciding with the default state. As a consequence, when the default-term-structure evolves, the pricing operated by the DA will allow at accumulating enough reserves or adjust pricing to maintain its financial equilibrium according to proposition (9) and eq.(14). 
What if, however, the events of default anticipate and are much more concentrated? Such an eventuality would violate the assumed hypothesis of infinite granularity of obligors, thus causing the DA to remain with insufficient accumulated reserves and with a lack of revenues to cover its future expected liabilities.

First of all, we should speculate what would be a default of a MS once the DA has been established. Should a MS incur in a status of insolvency, it is nonetheless likely that, under a suitable "ex-ante budget control regime" necessary to assure agency's ongoing correct operational course, the failing MS will soon or later be able to restart its ability to repay future installments, if not the ones overdue. This means that the MS would undergo a period of restructuring before full recovery (forbearance). During this period and only in it, the MS suffers from reduced ability to pay its installments. Therefore, the agency would not be able to maintain its equilibrium and to finance its funding costs.

It must however be observed that the distressed asset does not need to be written off. In reality, it will be simply "frozen" on the agency balance sheet during the forbearance period. Hence, the default state of a Eurozone MS is in reality a forbearance state. This allows us to maintain some essential features of our model, even outside the initial hypothesis of infinite granularity of obligors.

Hence, we are entitled to transform the granularity hypothesis into an equivalent one, according to which the debt of each MS is infinitely divisible into infinitesimal parts, which are supposed to be independent from each other only for mathematical convenience.

This methodological assumption allows us to proceed in our calculations as only a proportion of a MS's debt will be reported as a loss, according to the expected default probability of the rating grade class in any time interval $(t ; t+1)$ and that, as a consequence, the portfolio default probability will follow the process under (13). Thanks to this "fiction", the cost of debt would be re-estimated in each period only on the basis of the following risk factors:

1. the migration risk, when the agency asset allocation by rating classes is changed due to effective MS up-grade or down-grade, and

2. changes in the expected monetary policy rates of the Central Bank.

Following this line of reasoning, the repricing mechanism of the eq. (14) will ensure that the pricing operated by the agency allows the maintenance of its financial equilibrium. Additionally to this and in order to fully implement the highlighted setting, we need:

1. to adjust the annual pricing to take into account the theoretical loss as mentioned,

2. to allow for an insurance scheme aiming at providing financial support in the form of capital equivalent to the present values of annual payments lost during the forbearance period of a MS. 
For the first point, our fiction consists in imagining that a single MS $i$ with initial debt equal $D_{i j}$, representing a relevant fraction of a specific rating grade class $j$, will pay only for an amount determined using the partition rule under (12) adjusted in proportion to the theoretical default for each given interval $[t, t+1]$ as follows:

$$
\begin{aligned}
\tilde{c}_{i j}(t) & =\tilde{c}_{i j}(t-1)\left[1-E\left(c d p_{j}(t)-c d p_{j}(t-1)\right)\right]+ \\
& +r r_{W} D_{i j} E\left(c d p_{j}(t)-c d p_{j}(t-1)\right)
\end{aligned}
$$

where $\tilde{c}_{i j}(0)=\frac{D_{i j}}{\tilde{a}_{j}}$ according to formula (12), and $r_{j}, \tilde{a}_{j}$ and $c d p_{j}(t)$ are ratinggrade-class characteristic quantities the meaning of which we have widely discussed in the previous sections and $r r_{W}$ is the theoretical portfolio recovery rate. Note that $\lim _{t \rightarrow \infty} \tilde{c}_{i j}(t)=0$.

For the second point, agency will only need to relay upon an available capital endowment to cover the temporary shortage of cash inflow due by an MS in state of forbearance. This capital allowance, which takes here the form of an insurance, should then be proportional to the total annual cash flows at risk for a period of time, $f i$, that we call forbearance interval. The present value at time $t$ of future payments due during the forbearance in the interval $[t, t+f i]$ is:

$$
f p_{i j}(t)=\sum_{h=t}^{t+f i} \frac{\tilde{c}_{i j}(h)}{(1+\pi)^{h-t}}
$$

The periodic premium that should be paid is then given by:

$$
\operatorname{prem}_{i j}(t)=\frac{\sum_{\tau=t}^{+\infty}\left(\frac{f p_{i j}(\tau)}{(1+\pi)^{t}}\right)\left[c d p_{\text {stress }, j}(\tau+1)-c d p_{\text {stress }, j}(\tau)\right]-r m_{i}(t)}{a_{j}}
$$

Where $a_{j}$ is the $j$-th element of the vector $\mathbf{a}(t), \pi$ is a suitable discounting rate, and the $c d p_{\text {stress }, j}$ represents a stressed default probability obtained through the equation (2) by using a suitable confidence interval such that:

$$
P_{c d p_{w}}\left(x \leq c d p_{\text {stress }}\right)=\alpha
$$

with $\alpha$ a prudential probability threshold. The $r m_{i}(t)$ represents the cumulated mathematical reserve at time $t$ given by:

$$
r m_{i}(t)=r m_{i}(t-1)(1+\pi)+\operatorname{prem}_{i j}(t)-\mathbf{1}_{[f i]}(t) f p_{i j}(t)
$$

where $\mathbf{1}_{[f i]}(t)$ is equal to one when $t$ is the first year of a forbearance period. Note that this reserve is different from the reserve deposit $r s(t)$. To include the insurance premium, a suitable mark up should be considered by adjusting overall payments accordingly. The final cost for the MS $i$ of rating grade $j$ is then equal to: 


$$
\hat{c}_{i j}(t)=\tilde{c}_{i j}(t)+\operatorname{prem}_{i j}(t)
$$

If we define $\hat{I}_{F}(t)=\sum_{j=1, \ldots, n}\left[\tilde{c}_{i j}(t)+\operatorname{prem}_{i j}(t)\right]$ then the following chain of inequalities holds:

$$
\hat{I}_{F}(t) \geqq I_{F}(t) \geqq I_{W}(i)
$$

This shows that the economic equilibrium of the DA is assured.

Remark 12 Following proposition (5), we have shown that under the pricing configuration (12) the agency has the potential to generate a positive economic value of equity which in our numerical elaborations turns out to be of the same order of magnitude as the present value of future insurance premiums, partly mitigating the costs required to finance the aforementioned insurance scheme.

Another important source of risk for the agency is interest rate volatility. We argue that the agency architecture hereby proposed can be thought of as a shield to protect MSs against "liquidity spread risk", thanks to the link with the Central Bank and the insurance scheme to cope with unexpected sovereign default risk. Nonetheless, interest rate asymmetric movements can cause repricing risk. We supposed that the agency will roll over its debt by issuing bonds indexed to Central Bank prevailing fund rates, but there is always the possibility that alignment will fail to be effective. In this case the agency will always have the ability to reprise the total installment needed to restore its financial equilibrium, by applying the equilibrium formula under eq. (14).

\section{Numerical application}

The numerical application of the model is based on a simplified TTC transition matrix. This matrix has been estimated by us using publicly available data of rating grades assigned to sovereign debts by Credit Rating Agencies in the period 1993-2015 ${ }^{4}$. This period has been chosen to include aspects of relevant institutional changes (e.g. events such as the introduction of the euro or the Eurozone sovereign debt crisis).

\subsection{Perpetual annuities}

On the basis of the assumptions and formulas presented here, a projection has been carried out to show the long-term evolution (1000 years) of the economic

\footnotetext{
${ }^{4}$ It could be objected that the statistics relating to the default of sovereign debt reported in the transition matrix are not reliable, since the events are so rare that they can cause problems of robustness. This is in general a very well founded objection, but that does not concern the transition frequencies between rating grades, which are instead our main source of information to derive a reliable measure of the cost of risk associated with each sovereign debt. In fact, as our analyses and verifications show, there is a strong correlation between rating grade transition frequencies and credit cycle.
} 
balance sheet of the Debt Agency under different LGD hypothesis and exposure $T D=100$.

The TTC transition matrix has been decomposed as illustrated in eq.(3). A fundamental characteristic of the matrix is that it exhibits an almost zero oneyear default probability for ratings from AAA to BBB. This is not surprising, since investment-grade ratings in the medium-term should only be subject to migration risk (Table 1).

\begin{tabular}{lcccccccc}
\hline & AAA & AA & A & BBB & BB & B & CCC & D \\
\hline AAA & 0.96 & 0.04 & 0 & 0 & 0 & 0 & 0 & 0 \\
AA & 0.02 & 0.91 & 0.06 & 0.01 & 0 & 0 & 0 & 0 \\
A & 0 & 0.03 & 0.9 & 0.07 & 0 & 0 & 0 & 0 \\
BBB & 0 & 0 & 0.05 & 0.87 & 0.06 & 0.01 & 0 & 0 \\
BB & 0 & 0 & 0 & 0.05 & 0.85 & 0.08 & 0.01 & 0.01 \\
B & 0 & 0 & 0 & 0 & 0.07 & 0.89 & 0.03 & 0.01 \\
CCC & 0 & 0 & 0 & 0 & 0 & 0.38 & 0.42 & 0.19 \\
D & 0 & 0 & 0 & 0 & 0 & 0 & 0 & 1 \\
\hline
\end{tabular}

Table 1: Estimated TTC transition matrix

We simulated a portfolio of sovereign central government debts the mix of which, ordered by rating grades, corresponds to the Eurozone MSs in the 2018 (Eurostat, 2019) :

$\begin{array}{lllllll}\text { AAA } & \text { AA } & \text { A } & \text { BBB } & \text { BB } & \text { B } & \text { CCC } \\ 25 \% & 34 \% & 12 \% & 26 \% & 3 \% & 0 \% & 0 \%\end{array}$

Assuming a rate $\pi=50 \mathrm{bps}$, the table below displays the values of perpetual annuities and corresponding annual cost for 100 units of debt by rating grades class under different hypotheses of loss given default (LGD). Note that for $L G D=0$ the perpetual annuity corresponds to the value of $1 / \pi=200$ for unit of debt (Tables 2 and 3).

\begin{tabular}{lccccccc}
\hline LGD & $0 \%$ & $50 \%$ & $60 \%$ & $70 \%$ & $80 \%$ & $90 \%$ & $100 \%$ \\
\hline AAA & 200 & 140 & 132 & 125 & 119 & 113 & 108 \\
AA & 200 & 130 & 121 & 114 & 107 & 102 & 96 \\
A & 200 & 121 & 113 & 105 & 98 & 92 & 87 \\
BBB & 200 & 110 & 101 & 93 & 87 & 81 & 76 \\
BB & 200 & 95 & 86 & 78 & 72 & 67 & 62 \\
B & 200 & 85 & 76 & 69 & 63 & 58 & 54 \\
CCC & 200 & 62 & 55 & 49 & 44 & 40 & 37 \\
\hline
\end{tabular}

Table 2: Unitary Perpetual Annuity by LGD value 


\begin{tabular}{lccccccc}
\hline LGD & $0 \%$ & $50 \%$ & $60 \%$ & $70 \%$ & $80 \%$ & $90 \%$ & $100 \%$ \\
\hline AAA & 0.50 & 0.71 & 0.75 & 0.79 & 0.84 & 0.88 & 0.92 \\
AA & 0.50 & 0.77 & 0.82 & 0.87 & 0.93 & 0.98 & 1.03 \\
A & 0.50 & 0.82 & 0.88 & 0.95 & 1.01 & 1.08 & 1.14 \\
BBB & 0.50 & 0.90 & 0.98 & 1.07 & 1.15 & 1.23 & 1.31 \\
BB & 0.50 & 1.05 & 1.16 & 1.27 & 1.38 & 1.50 & 1.61 \\
B & 0.50 & 1.18 & 1.31 & 1.44 & 1.58 & 1.71 & 1.85 \\
CCC & 0.50 & 1.60 & 1.82 & 2.04 & 2.26 & 2.48 & 2.70 \\
\hline
\end{tabular}

Table 3: Annual Cost per 100 of capital by LGD value

\subsection{Insurance scheme}

We have also addressed the question of how costly should be the insurance scheme to manage the risk of restructuring MSs (forbearance).

To allow for a quantification of such a cost, we relay on the stressed scenario as elaborated by the ESRB (2018), which gives an estimation of the overall 5 -years stressed default probability of a European portfolio of sovereign debts, weighted by their outstanding amounts. We used this value for the DA's credit portfolio to calibrate stressed transition matrix in order to obtain a coherent PDs term structure to compute the insurance premiums according to the formula (17). From stressed cumulative default probabilities we can then infer the implied forward default probabilities needed. The tables (4) and (5) report respectively stressed cumulative default probabilities and an estimation of the premiums by rating grade class.

\begin{tabular}{lccccccc}
\hline Years & 1 & 5 & 10 & 15 & 20 & 25 & 30 \\
\hline AAA & $0.15 \%$ & $20.0 \%$ & $57.7 \%$ & $79.3 \%$ & $90.2 \%$ & $95.4 \%$ & $97.8 \%$ \\
AA & $1.0 \%$ & $31.6 \%$ & $66.4 \%$ & $83.7 \%$ & $92.3 \%$ & $96.4 \%$ & $98.3 \%$ \\
A & $2.8 \%$ & $40.6 \%$ & $72.0 \%$ & $86.5 \%$ & $93.7 \%$ & $97.0 \%$ & $98.6 \%$ \\
BBB & $8.4 \%$ & $50.9 \%$ & $77.5 \%$ & $89.2 \%$ & $94.9 \%$ & $97.6 \%$ & $98.9 \%$ \\
BB & $19.1 \%$ & $62.6 \%$ & $83.3 \%$ & $92.1 \%$ & $96.3 \%$ & $98.3 \%$ & $99.2 \%$ \\
B & $27.3 \%$ & $68.8 \%$ & $86.3 \%$ & $93.5 \%$ & $97.0 \%$ & $98.6 \%$ & $99.3 \%$ \\
CCC & $50.1 \%$ & $78.8 \%$ & $90.7 \%$ & $95.6 \%$ & $97.9 \%$ & $99.0 \%$ & $99.5 \%$ \\
D & $100 \%$ & $100 \%$ & $100 \%$ & $100 \%$ & $100 \%$ & $100 \%$ & $100 \%$ \\
\hline
\end{tabular}

Table 4: CDP Stressed 


\begin{tabular}{lccccccc}
\hline LGD & $0 \%$ & $50 \%$ & $60 \%$ & $70 \%$ & $80 \%$ & $90 \%$ & $100 \%$ \\
\hline AAA & 0.042 & 0.060 & 0.063 & 0.067 & 0.071 & 0.074 & 0.078 \\
AA & 0.047 & 0.073 & 0.078 & 0.083 & 0.088 & 0.093 & 0.099 \\
A & 0.053 & 0.087 & 0.094 & 0.101 & 0.107 & 0.114 & 0.121 \\
BBB & 0.061 & 0.111 & 0.121 & 0.131 & 0.141 & 0.150 & 0.160 \\
BB & 0.076 & 0.160 & 0.177 & 0.193 & 0.210 & 0.227 & 0.243 \\
B & 0.087 & 0.206 & 0.230 & 0.253 & 0.277 & 0.301 & 0.324 \\
CCC & 0.128 & 0.412 & 0.468 & 0.525 & 0.581 & 0.637 & 0.693 \\
\hline
\end{tabular}

Table 5: Premium per 100 of capital by LGD value

\section{Conclusions}

In this paper we present the design and functioning of a European Debt Agency. The DA is conceived as a market operator, owned by the MSs, with the public mission of aligning the cost of public debts of each Eurozone MS with respect to its own fundamental risk, and to thereby issue a common European safe asset, which the ECB is entitled to directly buy in order to guarantee that its yield be not superior to its nominal rate. The main objectives of the Debt Agency can be summarized in the following points:

1. to align the cost of Eurozone MSs public debts with their respective fundamental risk

2. to provide the European financial system with a common public asset capable of maintaining a high rating, even during extreme systemic crises.

3. to use the least amount of public guarantees possible

4. to smooth and eventually stop the divergence dynamic on the sovereign debt market due to liquidity risk

5. to break the doom-loop between public debt and national banking systems

As for the first point, we demonstrate how the risk filtering mechanism of the Debt Agency manages to reduce the cost of financing public debts by aligning the payment of the installments with the fundamental risk of each country. This mechanism resulted in the issuance of a plain vanilla bond which allows the Debt Agency to efficiently collect the funds necessary to finance member states with infinite maturity loans.

For what concerns the second and third point, the bond issued by the Debt Agency would have the characteristic of being a truly common European safe asset. In this sense, by pooling MSs' debts without mutualizing them, the DA acts, as previously hinted, as a "Synthetic Treasure" whose bonds can be directly bought by the ECB, thus fully acting as a CB in a Treasury-CB circuit

Our simulations show that, for a level of capitalization lower than the present endowment of the ESM, the Debt Agency is, right from its establishment, able 
to cope with systemic shocks, even extreme (i.e. even in the case of single or multiple defaults).

As for the fourth point, the presence on the sovereign debt market of an asset structurally safer and more stable than any individual Eurozone sovereign debt will gradually reduce to the minimum - until eliminating - the divergence dynamic on outstanding debt due to liquidity risk. This effect is due to the diminishing proportion of outstanding debt with respect to the debt held by the DA. This divergence-absorption effect, jointly with the ECB capacity to align the DA's bond's yield to its nominal rate, can help to manage the interregnum between the inception of the DA and its complete absorption of the MSs' debt. Mostly at the first stages there could be a potential "juniority effect" on the outstanding debt, leading to a potential explosion of the spreads. But there are several mitigating factors that can be evoked

1. since the DA buys the expiring debt at its renewal at its face value, the best strategy for each bond holder is to hold bonds to maturity

2. should they be traded, the outstanding bonds would "compete" with the newly issued DA's bonds, which should be used first, in a LIFO perspective (moreover, the DA can issue its bonds with different maturities according to the needs of the market)

3. since the "juniority effect" is necessarily diminishing with the progressive absorption of the outstanding debt in the DA, the ECB can act residually, as it already does, in order to prevent speculative rallies on the outstanding debt.

Finally, the safe asset issued by the Debt Agency would allow national banks to gradually replace national debt with safe European debt. The European banking system would benefit in several ways. The main ones concern the availability of excellent collateral for their daily activities, the settlement of a lower level of capital given the reduction in the risk of the assets held, as well as the possibility for banks and financial institutions to rely on a benchmark asset that would help them in pricing evaluations.

Undoubtedly, the solution hereby proposed is a medium-term one, since it requires some time to be implemented. However, its design is such that any emergency debt issue operated in the meantime can be subsequently absorbed in its normal functioning. In other words, it can give a stabilizing horizon to the emergency measures which are to be taken during these unprecedented difficult time.

\section{References}

[1] Bernanke B. S. (2005). "The global saving glut and the us current account deficit". Technical report, FED. 
[2] Beck T., Wagner W. and Uhlig H. (2011). "Insulating the financial sector from the European debt crisis: Eurobonds without public guarantees." VoxEU

[3] Blanchard O., Summers L.H. (2017). Rethinking Stabilization Policy: Evolution or Revolution? NBER Working Paper No. 24179

[4] Bonnevay F. (2010). "The argument for a Eurobond: A coordinated strategy for emerging from the crisis" Institut Montaigne Policy Paper . Paris: Institut Montaigne

[5] Brunnermeier, M. K., L. Garicano, P. Lane, M. Pagano, R. Reis, T. Santos, D. Thesmar, S. Van Nieuwerburgh, and D. Vayanos. (2011) "European Safe Bonds (ESBies"), Euronomics Group. Available at www.euro-nomics.com.

[6] Brunnermeier M. K., Langfield S., Pagano M., Reis R., Van Nieuwerburgh S. and Vayanos D. (2017) "ESBies: Safety in the Tranches" Economic Policy, 32 (90): pp. 175-219

[7] Caballero R. J., Farhi E. and Gourinchas P.O. (2017). "The Safe Assets Shortage Conundrum" Journal of Economic Perspective, 31(3):pp. 29-46

[8] Caballero R. J., Farhi E. and Gourinchas P.O. (2017). " Safe Asset Scarcity and Aggregate Demand", American Economic Review, 106(5): pp. 513-18

[9] Caballero R. J., Farhi E. and Gourinchas P.O. (2008). "An equilibrium model of "global imbalances" and low interest rates" American Economic Review, 98(1): pp.358-93

[10] Caballero R. J. and Farhi E. (2015) ."The safety trap" , Harvard University Working Paper n. 233766

[11] Carney M. (2019). "The Growing Challenges for Monetary Policy in the current International Monetary and Financial System", Speech given by Mark Carney, Governor of the Bank of England, Jackson Hole Symposium 2019, Bank Of England www.bankofengland.co.uk/news/speeches

[12] Constâncio, V. (2018) "Why EMU requires more financial integration", Keynote speech at the joint conference of the European Commission and European Central Bank, Frankfurt am Main, 3 May.

[13] Constâncio, V. (2019) "European financial architecture and the European safe asset" speech at the Conference on European Financial Infrastructure in the face of new challenges, Florence

[14] Claessens S., Mody A. and Vallée S. (2012) "Paths to Eurobonds," IMF Working paper n. 172

[15] De Grauwe P. and Moesen W (2009) " Gains for All: A proposal for a common Eurobond" , CEPS commentary, Brussels: Center for European Policy Studies 
[16] De Grauwe P. and Ji Y. (2018) " How Safe Is a Safe Asset? ", CEPS Policy Insight n. 2018-08. Brussels: Centre for European Policy Studies

[17] Delpla J. and von Weizsäcker J. (2010), "The Blue Bond Proposal," Bruegel Policy Brief

[18] ESRB HLTF (European Systemic Risk Board High-Level Task Force on Safe Assets) (2018). Sovereign bond-backed securities: A feasibility study. Frankfurt: European Systemic Risk Board

[19] ESRB (2018), "Sovereign bond-backed securities: a feasibility study". Volume II: technical analysis by ESRB High-Level Task Force on Safe Assets

[20] Farhi E. and Maggiori M. (2016), "A model of the international monetary system", National Bureau of Economic Research Working Paper, n. 22295

[21] Gabor D. and Vestergaard, J. (2018) "Chasing unicorns: The European single safe asset" Competition and Change, 22 (2). pp. 140-164

[22] Golec P. and Perotti E. (2017). " Safe asset: a review", ECB Working Paper n. 2035

[23] Gorton G., Le Wellen S. and Metrick A. (2012), " The safe-asset share". American Economic Review, 102(3): pp. 101-06

[24] Gorton G. and Ordonez G. (2014), "Collateral crises" American Economic Review, 104(2): pp. 343-78

[25] Gorton G and He P. (2016), "Optimal monetary policy in a collateralized economy" NBER working paper n.22599

[26] Gourinchas P.O. and Rey H. (2007), "From World Banker to World Venture Capitalist: U.S. External Adjustment and the Exorbitant Privilege." In G7 Current Account Imbalances: Sustainability and Adjustment, edited by Richard H. Clarida, 11-66. Chicago: University of Chicago Press

[27] Gros D. and Micossi S. (2009), "A Bond-issuing EU Stability Fund Could Rescue Europe," Europe's world, Spring, www.europesworld.org/NewEnglish/Home/Article/tablid/191/ArticleType /articleview/ArticleID/21306/Default. aspx

[28] Greenwood R., Hanson S. G. and Stein J. C. (2015) "A comparativeadvantage approach to government debt maturity." The Journal of Finance, LXX (4): pp. 1683-1722

[29] Giuzio M., Ferrari D. e Paterlinia S. (2016). " Sparse and robust normal and t- portfolios by penalized Lq-likelihood minimization", European Journal of Operational Research, 250 (1): pp. 251-261

[30] Hellwig C, and Philippon T. (2011), "Eurobills, not Eurobonds," VoxEU 
[31] IMF (2012). " Safe asset: a financial system cornerstone?" Chapter 3 in Global Financial Stability Report, Washington

[32] Juncker J.C. and Tremonti G.(2010). "E-bonds would end the crisis." Financial Times, December 5

[33] Krishnamurthy A. and Vissing-Jorgensen A. (2012). "The aggregate demand for treasury debt", Journal of Political Economy, 120(2): pp. 233-267

[34] Krishnamurthy, A. and Vissing-Jorgensen, A. (2015). The impact of treasury supply on financial sector lending and stability. Journal of Financial Economics, 118(3), pp. 571-600

[35] Krugman P.R. (1998). "It's Baaack: Japan's Slump and the Return of the Liquidity Trap," Brookings Papers on Economic Activity, 29(2), pp. $137-206$

[36] Leandro Á. and Zettelmeyer J. (2018-a). "The Search for a Euro Area Safe Asset". Peterson Institute for International Economics Working Paper n. 3. Washington: Peterson Institute for International Economics

[37] Leandro Á. and Zettelmeyer J. (2018-b)." Safety without Tranches: Creating a "Real" Safe Asset for the Euro Area". Center for Economic and Policy Research Policy Insight n. 93. Washington: Center for Economic and Policy Research

[38] Monti M. (2010). " A New Strategy for the Single Market". Report to the President of the European Commission, Jose Manuel Barroso, May

[39] Panetta F., Angelini P, Albertazzi U., Columba F., Cornacchia W., Di Cesare A., Pilati A., Salleo C. and Santini G., (2009)." Financial sector pro-cyclicality: lessons from the crisis", Questioni di Economia e Finanza (Occasional Paper Bannk of Italy) n.44

[40] Perillo E. (2020). "Pandemina e recessione: l'insostenibile leggerezza di un meccanismo di instabilità europea", Il Sole 24 Ore. Available at: https://www.ilsole24ore.com/art/pandemia-e-recessione-insostenibileleggerezza-un-meccanismo-instabilita-europea-ADg91JJ.

[41] Ubide A. (2015). "Stability Bonds for the Euro Area". Peterson Institute for International Economics. Policy Brief n. 15 . Washington: Peterson Institute for International Economics

[42] Zettelmeyer J. (2017). "A new fiscal governance for the eurozone." In Quo Vadis? Identity, policy and the future of the European Union, ed. T. Beck and G. Underhill. VoxEU.org eBook. 